\title{
Tracing the Impact of Culture in the Translation of Selected Advertisements between English and Arabic
}

\author{
Rafid A. Al-Rubaii \\ Department of Translation, Al-Ma'moun University College \\ Baghdad , Iraq \\ Corresponding Author: rafid.a.ghaeb@almamonuc.edu.iq \\ Hadeel N. Mohammed Saeed \\ Department of Translation, Al-Ma'moun University College \\ Baghdad, Iraq
}

Received: 4/2/2021

Accepted: 4/29/2021

Published: 5/24/2021

\begin{abstract}
The role of advertising across cultures can be touched upon quite differently. Therefore, translators should approach advertisements unequally in a particular culture. The translation of advertisement has gradually expanded as a result of the rise of globalization and trade intensification, and that necessitated that companies communicate with consumers of different cultures. The present study aims at investigating how sociocultural variables which play a vital role in advertisement are dealt with cross-linguistically. It first introduces a theoretical background that discusses the concept of culture and its impact on translation, as well as the major translation strategies used to deal with cultural issues. It, moreover, attempts to answer the question about how cultural variables affect the process of translation and the selection of an appropriate equivalent. To answer this question, seven ads, along with their translations, have been selected and subjected to a thorough analysis. The article comes up with some conclusions, the most important of which are: cultural domination plays a more pivotal role in translating ads than in other text types, that the translation strategies used for rendering an ad between English and Arabic range from literal translation to rewriting, with free translation to be of a higher frequency, that specific translation methods, such as transliteration, have been overused. Finally, the study has shown a growing tendency in Arabic to depart the traditional cultural aspects of writing and translating an ad and move towards those of the English-speaking culture.

Keywords: advertisements, Arabic-English-Arabic Translation, cultural domination, cultural diversity, translation strategies

Cite as: Al-Rubaii, R. A., \& Mohammed Saeed, H.N. (2021). Tracing the Impact of Culture in the Translation of Selected Advertisements between English and Arabic. Arab World English Journal for Translation \& Literary Studies 5 (2) 76-90.

DOI: http://dx.doi.org/10.24093/awejtls/vol5no2.6
\end{abstract}




\section{Introduction}

Translation is the conscious process of transferring a text or a speech from source language to target languages and cultures. Cultural diversity is considered the most difficult barrier in the process of translation. Culture is a key term in translation, and this significance led to the rise of the concept of cultural domination.

In some social philosophies, cultural domination results from the community's ruling class that controls and manages the cultural scene in the society, which eventually affected the middle and working classes. The cultural scene includes things like beliefs, explanations, perceptions, and values, manifested in aspects like individualistic vs. collective consciousness, low-context vs. high-context communication styles, literacy, etc. (see Bullock, 1999, and Sulaiman, 2014). In translation studies, however, cultural domination is the effect and interference of cultural aspects in the general use and perception of cross-linguistic communication. Here, the translator's competence or incompetence in dealing with cultural gaps between the two languages concerned play a pivotal role in the successful rendition of a text.

Translation between English and Arabic is one of the most complicated tasks as the two languages belong to different origins with remote cultures. This is very evident when ad translation is concerned, as ads belong to a discourse where cultural interference is most vivid (Dann, 1996). That is, advertisement discourse is deeply rooted in the domain of culture. Consequently, the main task of the translator is to reconcile the two languages to introduce a translation that is as original as the source text without a strong effect of inescapable cultural domination. This has called upon the translators of this discourse to avoid the linguistic approach, and seek, instead, for a more functional approach (Sumberg, 2004).

The present study investigates the role of culture in translating advertisements between English and Arabic with the aim of addressing some of the incongruences in dealing with ads through translation. More specifically, it attempts to answer the following questions:

1. What are the commonest cultural variables involved in the writing and/or translation of ads?

2. What are the strategies used for rendering an ad cross-linguistically?

\section{Literature Review}

\section{Translating Advertisements}

With a world of globalization and within everyday life, advertising has become an inescapable tool of communication that can be found everywhere in audiovisual and printed media, in sport on coach express and parking tickets, on $\mathrm{TV}$, in public and of course on the internet. In this connection, (Cook, 2001) wrote:

In contemporary society, advertising is everywhere. We cannot walk down the street, shop, watch television, go through our mail, log on to the internet, read a newspaper or take a train without encountering it. Whether we are alone, with our friends or family or in a crowd, advertising is always with us, if only on the label we are using". (P. 1) 
Translating advertisements is an arduous task since the persuasive power devices within advertising are notorious and not easy to translate. Advertising is "a microcosm of almost all the prosodic, pragmatic, syntactic, textual semiotic, even lucid difficulties to be encountered in translating." (Smith \& Klein -Barley, 1997:175, p. 175).

Al-Shehari (2000) has investigated the domesticating ads. In this respect, he says, "the translator should make changes to adverts translated to the Arab world, for instance, covering the naked body, removing taboo words, some Christian symbols in flags like cross, in order to make the advert look more Arabic" (p. 180).

Smith (2006) supports al-Shehari's opinion through focusing on making the translated ad look like an original text in the TL "advertisements as commercial texts written to persuade, should be translated in such a way that the target text functions within the target culture as though it were an original"(p. 161).

Ho (2014) investigated the translation of advertisements across heterogeneous cultures. He has first argued that translating does not serve the aim of publicity only; rather it adds economic value in the whole process of marketing chain. Thus, it is a key commercial activity. He has argued through the cases he studied that the translation of ads across heterogeneous cultures involves more than rewriting a text in a different language or even adapting a text culturally. It, moreover, involves mental and psychological conversion. Further, he argued that rewriting an ad in a TL with intentional major thematic and stylistic changes proved to achieve excellent results. Thus, he recommended that translators should cater more to the "popular test" of consumers than to other variables.

Al-Tameemi \& Farhan (2020) investigated the phonological problems of translating English international TV advertisements into Arabic. They have tackled the most common TV advertisements due to their immense influence on readers / listeners. They proceeded from the observation that the translation of an ad is a serious challenge since they cannot be translated without loss of meaning or form. They have found that certain linguistic elements (such as rhyme, rhythm, and alliteration) duplicate the impact of an advertisement on the domestic market, and that the more such elements are utilized properly, the more popular and influential an ad becomes.

\section{Headlines}

A headline is the most important linguistic element in advertising texts since, "headlines carry the persuasive content to encourage receivers to read on and hopefully, buy the product". (Smith, 2006, P. 60).

A headline usually plays a considerable linguistic role in advertising texts, because it is the decisive factor that persuades a potential customer to continue reading the rest of the text, and makes him buy a product. Headlines should attract attention, and be easily and quickly understood. Thus, one can confidently assert that headlines are extremely valuable assets for advertisements. 


\section{Rhetorical figures in advertising texts}

People have recognized the power of rhetoric as a means of persuasion since the time of Aristotle's seminal The Art of Rhetoric, written in $350 \mathrm{BC}$. Rhetorical figures have not only persuasive function but also impressive one in advertising. Since the main target of advertisement is persuasive, how the content is communicated "may be more important than its propositional content"(McQuarrie \& Mick.1996, p.424), as they "add strength to persuasive oratory" (Dyer, 1988, p.158). Put differently; rhetorical figures seem to be more exciting than conventional language; in a way that creates a more positive attitude towards the product. Accordingly, advertisers use them intentionally.

\section{Culture and Translation}

\section{The Role of Culture in Translation}

Culture plays an immense role in any act of translation. Rodriquez and Vidal (1996) maintain "Contemporary studies on translation are aware of the need to examine in depth the relationship between the production of knowledge in a given culture and its transmission, relocation, and reinterpretation in the target culture" (p.2). (Akbari, 2013) reformulated this opinion in a more technically way in defining translation from a cultural stand as the process "of cultural de-coding, re-coding and en-coding" (p.14).

Some have gone beyond this limit in assuming that the social context in translating a text may be a more critical variable than its genre (Hatim and Mason, 1990). Al-Hassan (2013), on the other hand, sees that "One basic purpose why we translate from language A into language B is to enrich linguistically and culturally language B.” (p. 96).

\section{Culture and Strategies of Translation}

Culture is the main gate through which the process of translation can be performed as it represents interweaved networks of life which includes multi-interdisciplinary activities. In translation, culture is a very critical issue as it deforms and facilitates the message conveyed by the interpreter from a source language into a target language. In this regard, Sapir (1949) mentions: "all human groups are cultured, though in vastly different manners and grades of complexity" (p.80).

Translation includes linguistic and cultural interference between the source language culture and the target language culture. Consequently, the translator has to adjust a new culture, without necessarily giving up one's first culture through creating a parallel atmosphere translation (DíazRico \& Weed, 2006). This parallel can be achieved through specific techniques and tips.

Ilyas (1989) maintains that "translation between languages of disjunct cultures is more difficult than carrying out translations between languages that are culturally related or similar" (p. 123).

In what follows is a brief account of the most common translation methods in as far as cultural interference is concerned. This should not be taken that these are the only methods used, rather they are found through a pilot investigation to be of frequently opted for while dealing with the cultural aspects of an advertisement. 


\section{Communicative Translation}

Peter Newmark was the first one who brought communicative translation into existence through the term of "equivalence "by investigating the relation between translation and source language, besides its relation to the meaning through making the translation idiomatic and free (Newmark, 1981). Communicative translation aims at producing the effect of the original text on the reader. In other words, the translated text must be as original as the source text. (Newmark, 1981). Communicative translation asserts the meaning rather than the content of the message; it adopts more energetic terms in difficult passages to convey the meaning of the text (Newmark, 1981).

In this method of translation, the translator has the right to add or remove certain lexical items to clarify the thought of the SL text to the target reader. In this sense, the translator becomes subjective, smoother and more direct. For this reason, Newmark prefers this method to the semantic one which is more text-bound.

\section{Domestication and Foreignization}

Venuti, an American scholar, was the first to put forward the concept of Foreignization and Domestication in translation studies. Foreignization is a source -culture oriented, by which the translator devotes serious efforts "to translate the source language and culture into the target one in order to keep a kind of exotic flavor"(Feng \& Jianwen,1993, as quoted in Wang,2014, p. 2424). Domestication, on the other hand, is a culture-oriented translation "in which unusual expressions to the target culture are transmuted and changed into some familiar ones so as to make the translated text easy to be understood by the target reader."(Wang, 2014, p.2424). These concepts of foreignization and domestication are directly related to translating advertisements.

\section{Over and Under Translation}

Cultural differences between the SL and the TL led to the advent of two translation strategies; over-translation and under-translation. The first is associated with the process of adding to the TL text to make it untestable and logical. The second, on the other hand, is related to the act of reducing the speech that the target language contains to be less than that of the source language. Initiated by Newmark (1976), these two concepts occupied a central position in the field of translation. The more linguistic and cultural differences exist between the SL and the TL, the more these two processes of over and under translation become necessary and apparent. Due to the immense cultural differences between English and Arabic and their impact on the writing and apprehending of advertisements, these two processes more often than not, appear to be inescapable.

\section{Transliteration}

Pillar (2010) maintains that some transliterations of ads can fit the patterns of the Arabic language in a better and more comfortable manner than others. Yet, they are still considered as loan words and" insert a foreign or exotic element into the Arabic language", although some Arabic speakers may find them annoying.

Al-Agha (2009) claims that this type of advertising is explicitly "rejected by the target culture" (p. VI). However, with certain advertisements of global status brands which seek to distance 
themselves from all forms of cultural domination, transliteration becomes an indispensable method of rendition.

\section{Methodology and Data Analysis}

To answer the questions of this study, a large number of ads were selected and thoroughly studied at an initial stage. At a later stage, seven ads along with their translations have been selected to be the study data. The selection was based on the criterion of cultural variables coverage (i.e. these seven ads have been concluded to cover the main cultural dichotomies aimed at in this study). The ads are bi-directional (i.e., some are written in English and translated into Arabic, while others adopt the opposite direction).

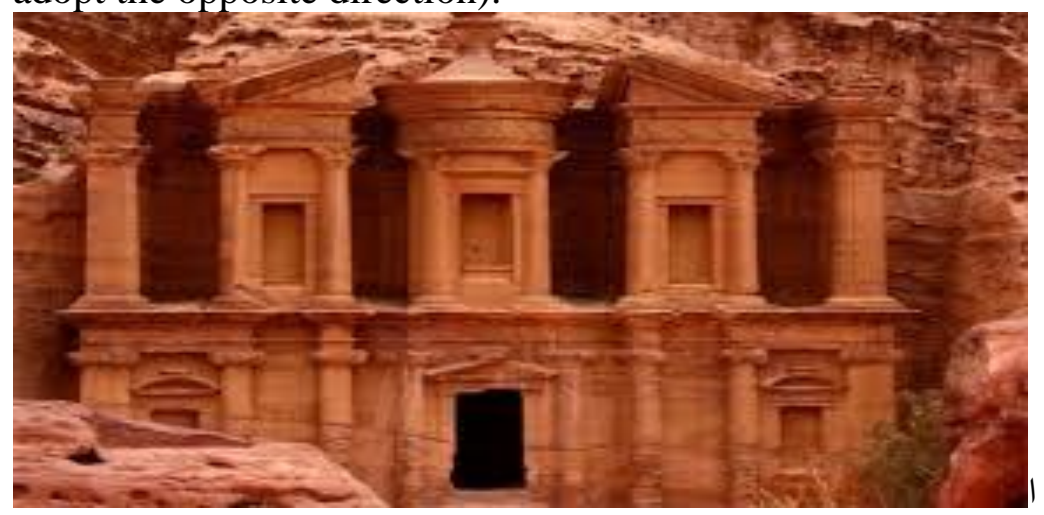

Figure (1). Petra

This tourist promotional advertisement is about Petra of Jordan which has been recently chosen as one of the new Seven World Wonders. In Arabic it is given the headline البترا: مدينة وردية، عمر ها and it is translated into Petra: a rose-red city, half as old as time. The SL text is Arabic and English is the translated version of the advert. A quick look shows two important points; on the one hand it is translated with adaptation to the extent that one can infer the loose translation it implies, and this is permissible, for in the translation of a tourist text, the idea of adaptation area is interpolated with the issue of rewriting because different cultural backgrounds are involved, and this entails that different psycho and socio-economic factors interfere (Fan, 2017). On the other hand, this tourist ad shows vividly the cultural load it implies and its impact on translation.

Firstly, the Arabic text identifies Petra as مدينة وردية (pink color) which is not the exact color as the photo shows. The city's actual color is crimson; a color associated with melancholy in the Arab culture, and it has been avoided as it does not serve the promotional target intended. This case led to the use of a color that has much positive cultural connotation and which, at the same time, shares some aspects with the color crimson. The English version, however, adopts another, different choice of the language's color system, namely rose-red which shares more features with the city's actual color than the SL text's choice does. The TL's choice, moreover, implies much emotional charge equivalent to that indicated in the SL version, but at a different level of factuality.

As for the second part of the ad, it talks about the city's history which is highly significant in promoting any archaeological site. The SL version, Arabic, uses a high-level hyperbole through equating the city's age to the entire world's recorded history عمرها من عمر الزمن which is far from 
being the fact, as the world's recorded history is estimated at 5500 years, while the city's recorded age is 2400 years.

This difference shows the following points:

1. The SL version uses a higher level of exaggeration, while the TL version uses a milder level of exaggeration.

2. The first point further validates Sulaiman's observation (2014) that the Anglophone society is highly literate and that this literacy is usually treated, for the purpose of advertisement, at the secondary level. This means that the factuality of an utterance is compounded with an appealing, acceptable level of exaggeration.

One can then conclude that the translation of this tourist ad adopts the perlocutionary equivalence, which is a kind of equivalence that relies mainly on socio-cultural factors (see Hickey, 2001; 2004).

Figure 2. Burger King

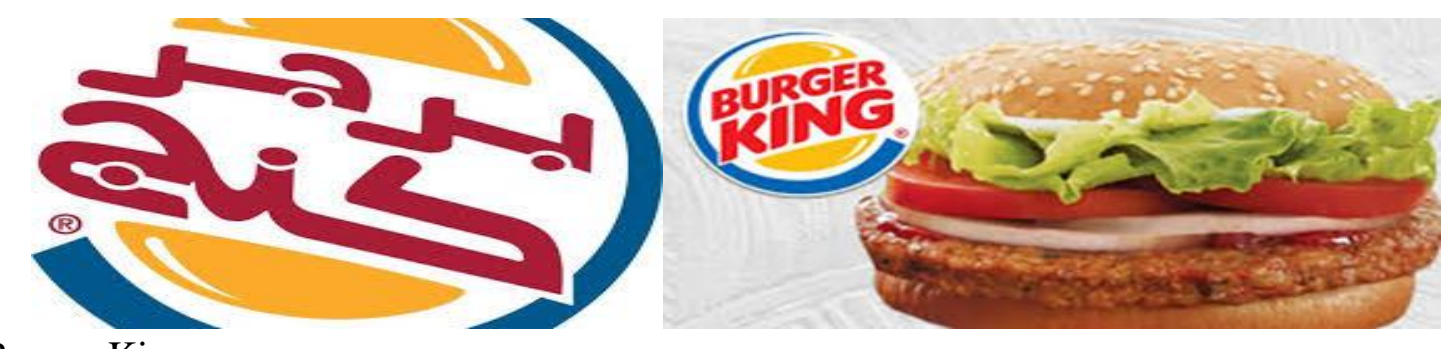

This commercial advertisement is about a globally recognized meal, namely that of Burger King. Etymologically the word Burger or Hamburger is derived from Hamburg, the name of a German city where this kind of meal was first served (Harper, 2009). After that, the meal with the current brand has expanded as a slogan of the dominant Western-American lifestyle. In Arabic, the exact translation of Burger or Hamburger is فطيرة لحم بقري (i.e., paraphrase) as this word has no exact equivalent in Arabic due to the non-existence of this kind of meal. However, the paraphrase mentioned above does not serve the promotional purpose for two reasons:

1. Such a translation is ambiguous and misleading because it could refer to any slice of meat, not necessarily the intended one.

2. It violates one of the essential characteristics of a good advertisement, namely that of brevity.

To this end, transliteration has been opted for as the most suitable way of rendering it into Arabic. As for the second word of the ad King, it is also transliterated, although there is an exact equivalent for the term in Arabic مل There are two reasons behind resorting to the method of transliteration here:

1. To preserve the cultural identity of the brand.

2. To achieve the feature of unfamiliarity (i.e., linguistic markedness), which is considered one of the most appealing characteristics of ads (see Hatim, 2004). 
However, it is worth mentioning that برجر كنج is an instance of partial, rather than total, transliteration as the English $/ \mathrm{g} /$ is realized as $\mathrm{r}$ due to the non-existence of $/ \mathrm{g} /$ in the sound system of Arabic. Thus, transliteration is one of the essential techniques of rendering commercial advertisements, used for keeping the identity of the product and for standardizing the brand name worldwide. Consequently, transliteration in commercial advertisements reflects the cultural as well as socio-economic domination in terms of globalization.

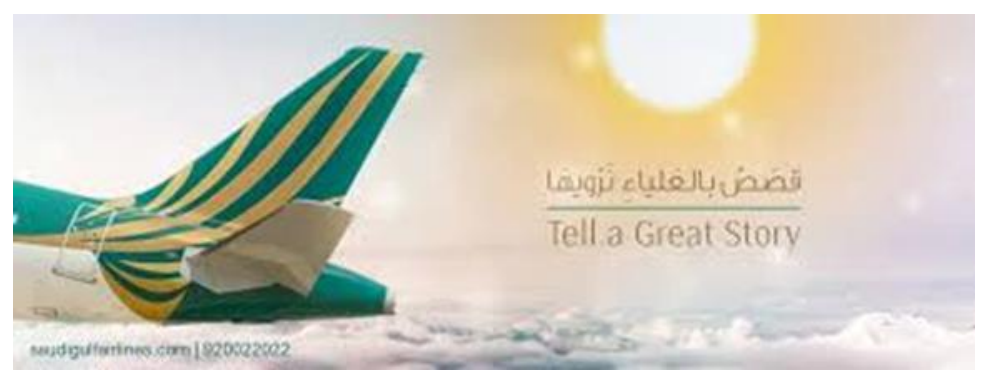

Figure 3. Saudi Airlines

This ad promotes Saudi Airlines. The source language of the text is Arabic, whereas the target language is English. The slogan is in Standard Arabic. It adopts a highly rhetorical language. First, it is a visually aided ad in that the photo, in both the SL and the TL, is an integral part of the ad. In the SL the picture tells us what the entire matter is. In other words, if it had not been for the picture, the whole ad would have been ambiguous for the entire readership, particularly for the potential customer to whom the ad is intended. As for the TL text, the photo acts as the subject for which the written text is the predicate. The slogan adopts inversion or anastrophe in Arabic. Inversion is a literary technique in which the standard order of words is reversed, to achieve a particular effect of emphasis or meter (Garrity, 2000). The inversion here aims at:

1. Reinforcing the rhetorical power of the Arabic language as a significant cultural concern.

2. Achieving the feature of unfamiliarity (i.e., linguistic markedness) to attract the reader's attention.

As for word selection, the SL text adopts the highly desired word being a word with much literary connotation that appeals deeply to the Arabs' passion.

However, the slogan, قصص بالعلياء نرويها is translated non-literally into "tell a great story", whose back translation would be one like "تروي قصة عظيمة" " تروية "The TL version seems less imaginative than its SL counterpart, thus the socio-cultural consciousness of the TL reader is addressed, namely that of focusing more on the factual aspect of the text than on its imaginative aspect. 


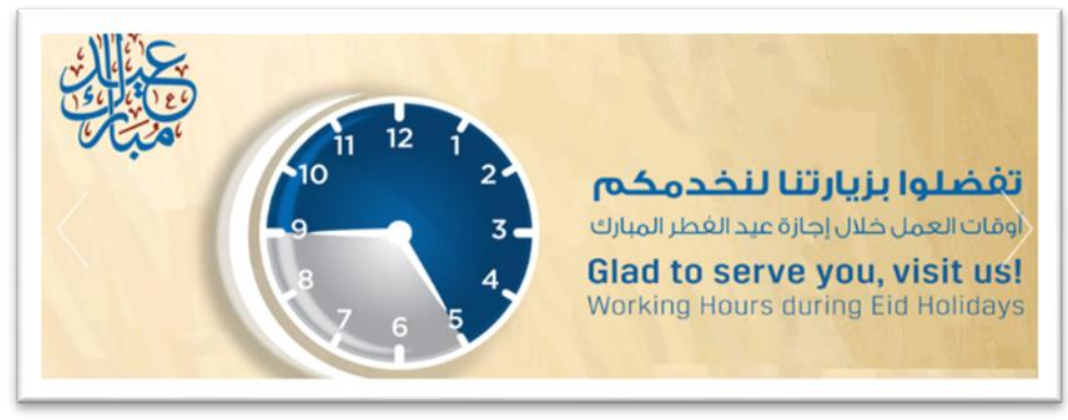

Figure (4). Eid Holiday

The SL text of this ad is Arabic and English is the TL text. It consists of two parts, primary and secondary, and each part is analyzed separately. As for the SL (i.e., Arabic), it follows the routine sequencing of events, the addressee is first invited to visit the place, followed by announcing full readiness to introduce a high-level service. The potential customer is addressed in the plural. This is in line with the collective consciousness (i.e., a high-context communication style), which is a socio-cultural characteristic feature of the Arabic-speaking communities.

The translation, on the other hand, shows the following:

- The second component is foregrounded (i.e., linguistically marked) to attract the customer's attention. This leads us to conclude that the TL version is relatively more attractive than its SL counterpart.

- Addressing the second person in the TL linguistic system you is unified for both singular and plural. This linguistic potential is used to meet the socio-cultural feature of Englishspeaking communities, namely that of individualistic consciousness and ego-targeting (see Dann, 1996). Thus, English, unlike Arabic, is labeled as a language of low-context communication style usually pertinent ego-targeting mode of address (Reisinger \& Turner, 1997).

- Related though to the second point is the omission of the culturally courteous word in Arabic تفضلوا, which has no literal counterpart in the socio-cultural system of English, and thus replaced by the functional (perlocutionary) equivalent Glad. This also serves the general tendency of low-context communication style in English, namely that of informality, as the Arabic تفضلو is highly formal.

- Dividing this part into two interrelated subparts serves the ego-targeting feature of the target culture through directly addressing the potential customer, once linguistically in Glad to serve you and the second time contextually through using the imperative form of the verb visit in visit us.

As for the second part of the ad, the SL text (Arabic) specifies the working hours through الفطر (Eid al-Fitr or the Lesser Bairam). The TL text adopts the rhetorical feature of synecdoche (using the part to refer to the whole and vice versa) to include both Eids (al-Fitr and al-Adha or the Lesser Bairam and the Greater Bairam). Thus, the TL adopts the strategy of over-translation in the rendition of this component of the second part of the text. 

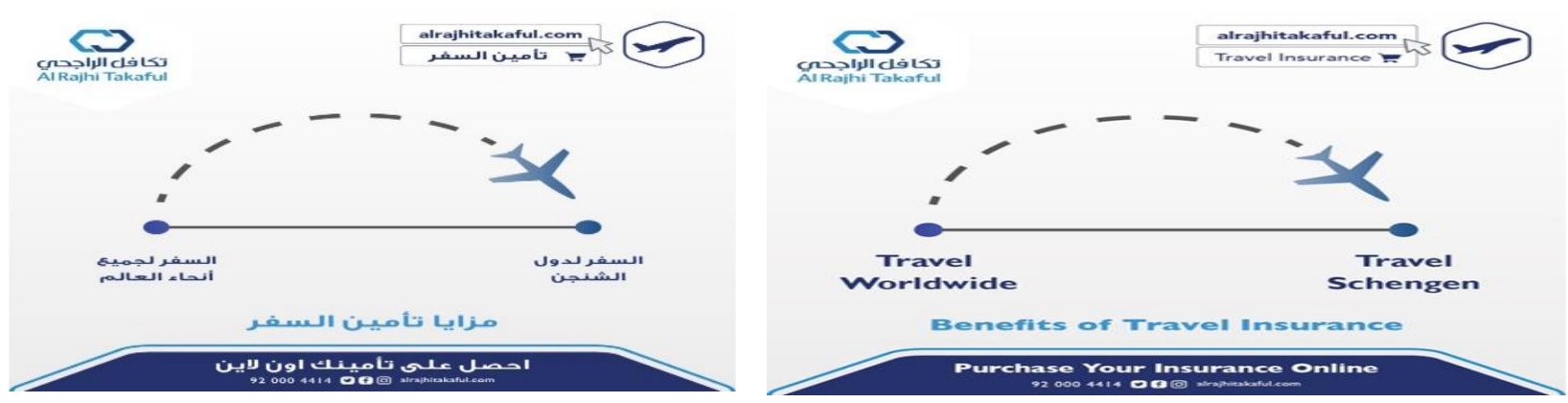

Figure (5). Saudi Airlines Insurance

There are three significant points of cultural domination concerning the above advertisement. Firstly, the Islamic-Arab culture reflects itself vividly through the use of the term تكافل (Takaful), which is borrowed from Islamic law (sharia'). Here functional equivalence is opted for in the translation of this term. In this respect, Kagan (2019) maintains that Takaful is a form of Islamic insurance in which a customer contributes money into a pool system to keep a source of guarantee in cases of loss or damage. However, the Arabic version uses the word تاحصل على تأمينك in interchangeably with the word تكافل اونلاين to indicate the sameness of meaning.

Secondly, the SL text (i.e., Arabic) reflects a new trend which is growingly in use in the Arabic ads, namely that of the use of the verb in the imperative form to directly and informally address the second person. This represents a change of attitude towards collective vs. individualistic consciousness discussed above in favor of the culturally dominant aspect of the English-speaking community of favoring the individualistic and ego-targeting mode of addressing. Such a mode of addressing is more influential in that it gives the potential customer a feeling of standing out of a crowd (Francesconi, 2007). Put differently, the function here 'is less an order than an invitation, which lacks the sense of compulsion' (Francesconi, 2007, p.109). In addition to its dialogic function, the imperative voice is also employed for another function which is of no less importance: that is, to evoke a sense of action and adventure. The imperative also lends the discourse a confidential, direct, and explicit tone consistent with the individualistic and low-context characteristics of Anglophone societies. Moreover, this change in attitude represents a move towards globalization, where ad addressing is unified.

Thirdly, the word احصل and its English equivalent Buy is an example of high- context vs. lowcontext communication style. The Arabic version does not directly mention the financial aspect of getting the insurance, rather it implicitly suggests so through احصل (get), and this is a characteristic feature of high-context communication style languages, of which Arabic is one. The TL version, however, and in concordance with the low-context communication style explicitly mentions the financial aspect of getting insurance through the use of the word Buy.

Finally, the use of the two transliterations of شنجن and اونلاين in the SL version represents the global cultural hegemony of the English-Western culture. Either of the two alternatives عبر الانترنت or" الكترونياً is appropriate; however, the cultural hegemony of some English expressions such as "online," "Schengen," etc. makes the transliteration of the English term the most appropriate one. 


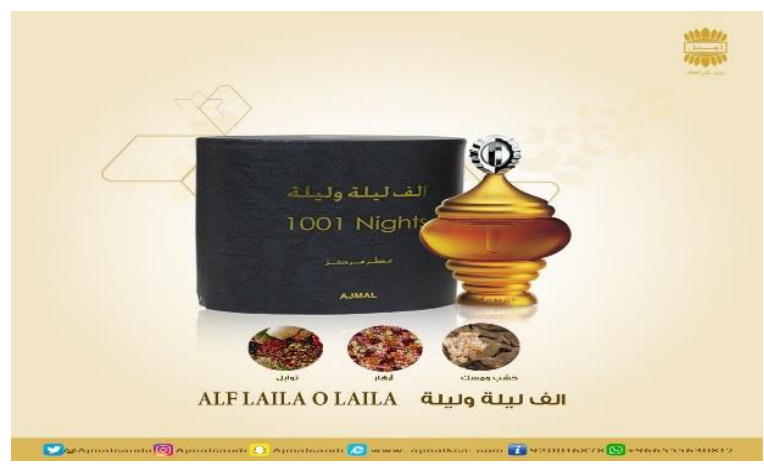

Figure (6). Alf Laila O Laila Perfume

The above commercial advertisement is about an oriental Perfume "ألف ليله وليله." Culturally, One Thousand and One Nights is a collection of oriental folk tales compiled in Arabic during the Islamic Golden Age (c. 1706 - c. 1721) (Ulrich, 2007). Here, the translator does not adopt the communicative Western equivalent of " that is known as "Arabian nights." Instead, he uses the transliteration of the term, Alf Laila O Laila; however, this transliteration is clearly meant to initiate a new brand departing from the traditionally or classically recognized translation affected by Google translation and digital sets of translation as it represents a very poor conversion of a text. Moreover, unfamiliarity is one of the basic tenets of successfully publicizing an ad.

Besides, and like Burger King discussed above, originality and unity of the brand is an essential element in marketing. In other words, it will not be acceptable to use two names for the same brand: the original Arabic one, ألف ليلة وليلة and the translated one "Arabian Nights." Here, translators aim to domesticate their brand for commercial purposes.
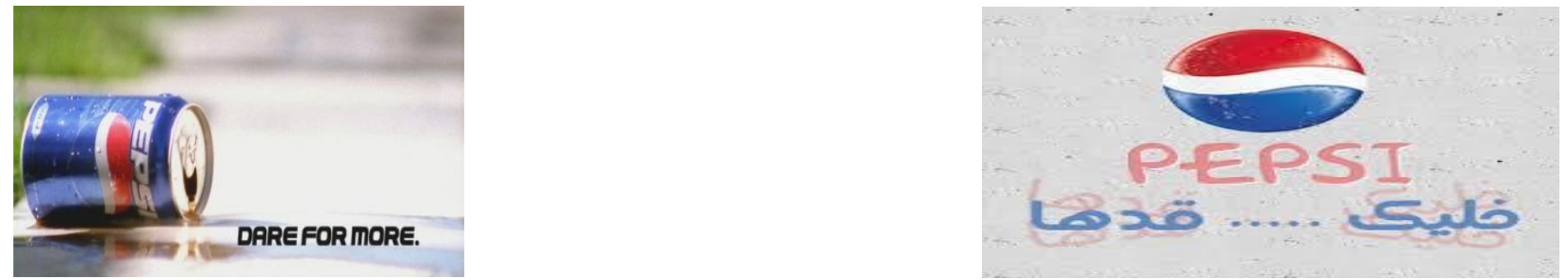

Figure (7). Pepsi

In 2004, Pepsi launched a commercial campaign, using the slogan dare for more to announce the company's new fashionable can. The campaign was regarded as one of the most extensive commercial campaigns ever. The slogan, advertisements, and posters of the campaign were widespread all over the world. On the cultural level, Pepsi Middle East adopts Egyptian Arabic as it is considered the most widely understood first dialect in the Middle East, probably due to the influence of Egyptian literature and cinema throughout the Arabic-speaking world.

The method of translation used here is that of functional equivalence; where the widely used formula of خليك قدها performs the same function as that of the SL version Dare for more. The 
immediately noticeable aspect of the Arabic translation is that it represents a departure of the classically used collective consciousness and high-context manner of communication style. Thus, the Arabic version uses the second person singular imperative form خليك, a mode which has been evidenced to be more appealing to the potential customer in issuing ads. Thus the Anglophone culturally dominant aspect seems to have affected the way an ad is produced in Arabic.

\section{Discussion}

The study has examined a number of cultural variables in the analysis of seven ads as translated between English and Arabic, namely individualistic vs. collective consciousness, ego-targeting, formality and literacy. It has been shown that English and Arabic are heterogeneous in as far as the realization of these cultural variables are concerned. This heterogeneity has had its influence on rewriting an ad in the other language.

In the first ad on Petra, the psychological disparity of appreciating a color has interfered in the rendition of the color in the first part of the ad, while literacy vs. literariness has played a role in rendering the second part of the ad. The ads of Burger King (Figure 2), Alf Laila O Laila (Figure 6) and Pepsi (Figure 7) use transliteration as a means of rendering them cross-linguistically since these ads deal mainly with brand names to be publicized on an international level due to globalization.

Religion plays a role in advertisement as shown in ad (5) where تكافل, which is of religious overtone, is rendered properly into the English insurance. Literariness manifests itself clearly in ad (3) where قصص بالعلياء نرويها is more literary in nature with a specific rhythmic pattern and more or less expressive in function than its English counterpart tell a great story, which is more informative than expressive, although both are intended for persuasive function. Formality is one of the features of high-context communication style languages, Arabic in our study. This feature shows itself vividly in ad (4) with the use of the highly formal term تفضلو, which is overlooked in translation due to the fact that English is one of the low-context communication style languages.

\section{Conclusion}

The present study has investigated seven ads to determine the frequent cultural variables that interfere in their translation between English and Arabic. It moreover endeavored to specify the translation strategies employed in rendering these ads. The study has come up with a number of conclusions. All the findings are exclusive of the ads discussed in this paper. The most important conclusions are:

1. Culture plays a significant role in writing and translating ads, because the main aim of an ad is to turn a potential customer into a real one. To do so, basic customer's needs should be met, and all these needs fall within the domain of culture.

2. The translator's choice in translating an ad is situated on a relatively broader scale of options than in the translation of other text types. It ranges from commitment to the SL to an almost total departure.

3. It follows that the strategies used by translators of ads ranged from literal translation to rewriting. However, the functional approach is the most opted for one. 
4. There is a growing tendency in Arabic to use the imperative form verb in the singular (ads 5 and 7), a feature which is pertinent to the Anglophone communities. This indicates that the addressee's individualistic consciousness and ego-targeting are given more attention, bringing distances closer between English and Arabic in the area of socio-cultural aspects of promotional advertisement writing.

5. Domestication and foreignization are extensively used depending on the context of an ad to achieve a higher level of persuasion.

6. Transliteration is frequently opted for in ad writing and translation. This adds a global feature to the terms and language of advertising. In other words, there is a tendency to globalize the language of advertisement.

\section{About the Authors}

Rafid A. Al-Rubaii, a PhD holder in translation since 2000. He worked in a number of state and private universities inside Iraq and abroad. Interested mainly in Media Translation, he wrote a number of articles in this specialization in addition to legal, religious and cultural issues in translation. Currently, he is working at Al-Ma'moun University College, Baghdad, Iraq. ORCID ID: https://orcid.org/0000-0002-9910-455X

Hadeel N. Mohammed Saeed, an MA holder in translation. Currently, she is working at a AlMa'moun University College. She is mainly interested in writing on cultural issues in translation. She has a number of conference participations in Iraq and abroad, and published a number of articles on translation in local and regional journals and conference proceedings. ORCID ID: https://orcid.org/0000-0002-9008-5065

\section{References}

Akbari, M. (2013). Strategies for Translating Idioms. Tehran: Islamic Azad University. Al-Hassan, A. (2013): The Importance of Culture in Translation: Should Culture be Translated? International Journal of Applied Linguistics \& English Literature, 2(2); March 2013 Australian International Academic Centre. Available at https://www.journals.aiac.org.au/index.php/IJALEL/article/view/910

Al Agha, B. A. (2009). The translation of fast-food advertising texts from English to Arabic.

(Unpublished Doctoral Dissertation). University of South Africa, South Africa. Available http://uir.unisa.ac.za/bitstream/handle/10500/2325/dissertation.pdf?sequence=1

Al Tameemi,I. M., \& Farhan, M. A. (2020). Phonological Problems of Translating English Advertisements into Arabic. Arab World English Journal for Translation \& Literary Studies 4(1), 52-69.

Al- Shehari, K.(2000): The Semiotics and translation of advertising texts: conventions , constraints and translation strategies with particular reference to English and Arabic. (Unpublished Master's Thesis). University of Manchester: UNIST.

Bullock, A. \& Trombley, S. (1999): The New Fontana Dictionary of Modern Thought ( $3^{\text {rd }}$. ed.). London: Harper Collins Publishers.

Cook, G. (2001). The Discourse of Advertising (2 $2^{\text {rd }}$ ed.). London: Routledge.

Dann, G. (1996). The Language of Tourism: A Sociolinguistic Perspective. Wallingford: CAB International. 
AWEJ for Translation \& Literary Studies Volume, 5 Number 2. May 2021

Díaz-Rico, L. T., \& Weed, K. Z. (2006). The cross-cultural, language, and academic development handbook ( $3^{\text {rd }}$ ed.). Boston: Allyn and Bacon.

Dyer. G.(1988). Advertising as Communication. London: Routledge.

Fan, H. (2017). Strategies for Translation of English Commercial Advertisements from the Intercultural Perspective. Open Journal of Social Sciences, 5 (11), 38-45. Available at https://m.scirp.org/papers/80167

Francesconi, S. (2007). English for Tourism Promotion: Italy in British Tourism Texts. Milano: Hoepli.

Garrity, N. (2000). Classic Middle School Literature . Good year Books. Available at https://www.amazon.com/Classic-Middle-School-Literature-2000-0503/dp/B01FGQ0GKQ

Harper, D.(2009). "hamburger". Online Etymology Dictionary. Available at https://scholar.google.com/scholar?q=Harper+2009+hamburger\&hl=en\&as_sdt=0\&as_vi $\mathrm{s}=1 \&$ oi=scholart

Hatim, B. \&Mason, I.(1990): Discourse and the Translator. London: Longman.

Hatim, B. (2004). "The Translation of Style: Linguistic Markedness and Textual Evaluativeness". Journal of Applied Linguistics, 1(3), 229- 246. Available at https://journal.equinoxpub.com/JALPP/article/view/13116

Hickey, L.(2001). "Perlocutionary Equivalence: Marking, Exegesis and Recontextualisation". In L. Hickey (Ed.), The Pragmatics of Translation (pp. 217-232). Clevedon: Multilingual Matters.

Hickey, L. (2004). "Perlocutionary Pursuits: Persuading of/that/to". In M. P. N. Errasti, R. L. Sanz \& S. M. Ornat (Eds.), Pragmatics at Work: The Translation of Tourist Literature (pp. 5779). Bern: Peter Lang.

Ho, George (2004). Translating Advertisements across Heterogeneous Cultures. The Translator, 10 (2), 221-243.

Ilyas, A. (1989). Theories of Translation. Mousil: University of Mousil.

Kagan, J. (2019). Investopedia. Available at: https://www.investopedia.com/contributors/53409/.

McQuarrie, E. F. \& Mick. D. G. (1996). Figures of Rhetoric in Advertising Language. Journal of Consumer Research, 2 (2), 424-438.

Newmark, P. (1976). The Theory and the Craft of Translation. Cambridge: The University Press. Newmark, P. (1981). Approaches to Translation. Oxford: Pergamon Press.

Pillar, I. (2010). Transliterated Brand Names. Available at:

https://www.languageonthemove.com/transliterated-brand-names/

Reisinger, Y., \& Turner, L. (1997). "Cross-Cultural Differences in Tourism: Indonesian Tourists in Australia". Tourism Management, 18(2), 139-147. Available at https://www.sciencedirect.com/science/article/abs/pii/S026151779600115X

Rodriquez, R.A. \& Vidal, M.C.A.(1996). Translation,Power,Subversion. Clevedon: Multilingual Matters.

Sapir, E. (1949). Culture ,Language, and personality. California: The University Press.

Smith .V, \& Klein,M. (1997): Advertising-A five strategy for Translation. Translation as Intercultural Communication. Amsterdam: Philadelphia.

Smith, P. (2006). Book reviews. Journal of Product Innovation Management, 23(2), 191-193. Available at https://doi.org/10.1111/j.1540-5885.2006.00192_1.x.

Arab World English Journal for Translation \& Literary Studies 
AWEJ for Translation \& Literary Studies Volume, 5 Number 2. May 2021

Sulaiman, M. Z. (2014). Translating the Style of Tourism Promotional Discourse: A CrossCultural Journey into Stylescapes. In Procedia-Social and Behavioral Sciences, 118, 503510. Availableat www.sciencedirect.com

Sumberg, C. (2004). Brand Leadership at Stake: Selling France to British Tourists. The Translator, 10(2), 329-353. Available at https://www.tandfonline.com/doi/abs/10.1080/13556509.2004.10799183

Ulric, M. (2007). The Arabian Nights in Transnational Perspective. Wayne: The State University Press.

Venuti, L.(1995) The Translator's Invisibility. London: Rutledge.

Wang, F. (2014). An Approach to Domestication and Foreignization from the Angle of Cultural Factors Translation. Theory and Practice in Language Studies. 4 (11), 2423-2427. Available at https://www.semanticscholar.org/paper/An-Approach-to-Domestication-andForeignization-the-Wang/b7b1aa53b24e6d964e84326cfaf0066e2462e9d 